\title{
Los mártires de la UCA Exigencia y gracia
}

\author{
Jon Sobrino, \\ Centro de Reflexión Teológica, \\ San Salvador.
}

Hace veinte años asesinaron a mis hermanos jesuitas de la UCA, a Julia Elba y Celina. Yo estaba en Tailandia, y de regreso a El Salvador tenía que pasar por San Francisco. En el aeropuerto me esperaban, con rostros impávidos, Steve Prevett y Peggy O'Grady. En las calles de San Francisco, con un parlante en la mano, Paul Locatelli condenaba los asesinatos, y Tessa Rouverol le acompañaba. Me trajeron a la Universidad de Santa Clara. La comunidad me acogió como a un hermano y en ella pasé varias semanas. Cuando llegué, me encontré con ocho cruces plantadas delante de la iglesia. Y cuando un desalmado las arrancó, Paul Locatelli inmediatamente las volvió a plantar. Nunca lo olvidaré. Por eso, ahora tengo un sentimiento de "volver a casa".

Sobre estos mártires quiero hablarles, con agradecimiento por lo que fueron e hicieron, pero también con la convicción de que es vital mantenerlos vivos y de que sería fatal dejarlos morir. Los mártires, ellos y ellas, nos confrontan con nosotros mismos sin escapatoria, iluminan las realidades más profundas de nuestro mundo y lo que hay que hacer con él. Tenemos que enfrentarnos a los ídolos que exigen víctimas en el Tercer Mundo, aunque sus raíces más hondas están en el Primero, y tenemos que trabajar por revertir la historia y salvar así a una civilización que está gravemente enferma, como decía Ignacio Ellacuría, a un mundo en trance de muerte, como dice Jean Ziegler. A los cristianos, los mártires nos señalan, mejor que nada y sin temor a equivocarnos, el camino a seguir. Son los que más nos empujan al seguimiento de Jesús y mejor nos introducen en el misterio de su Dios.

En el mundo que llamamos de abundancia, la palabra "mártir" produce extrañeza, incluso repulsión, pero entre nosotros - y aquí asoma la paradoja cris- 
tiana - también produce luz, ánimo y agradecimiento. Por eso no debiéramos permitir que la palabra "mártir" pierda su vigor. Debe mantenerse como referente cristiano y social insustituible para humanizar a este mundo. Exactamente como la cruz de Jesús. Por esa razón hablaré ahora sobre los ocho mártires de la UCA.

Para ponerlo en un contexto no sólo académico, sino humano, comienzo recordando cuál fue la reacción de dos personas bien conocidas ante sus muertes. Uno, el padre Arrupe. Cuando los mataron, estaba ya en cama, prácticamente sin poder pronunciar palabra ni comunicarse. Cuenta el enfermero que, al darle la noticia, "el padre Arrupe se echó a llorar". Era todo lo que podía hacer, pero en el llanto se dio a sí mismo por entero. El otro, Noam Chomsky. Al cumplir 80 años en marzo de este año, un periodista le preguntó qué le daba fuerza para continuar en la lucha. "Imágenes como ésa", respondió, y señaló con la mano un cuadro en el que aparece el arzobispo Romero y los seis jesuitas de la UCA.

Estos seres humanos tocan las fibras más hondas de cualquier persona honrada. Son un referente vivificante. Ciertamente, los seis jesuitas. Y también Julia Elba y Celina, aunque estas siempre nos dejan en un silencio mayor, pues en ellas se hace presente el mysterium iniquitatis de manera más irritante.

\section{Quiénes fueron}

La injusticia da muerte a gente inocente de formas distintas. Mata a personas como monseñor Romero y Martin Luther King. Y lenta o violentamente, da muerte a grandes mayorías; a los campesinos de El Mozote en El Salvador; antaño, a los esclavos de las plantaciones de algodón.

\section{Los jesuitas de la UCA, mártires jesuánicos}

Comenzamos con los seis jesuitas. Después de Medellín, en 1968, y tocados por el sufrimiento del pueblo, "se convirtieron". Aceptaron que ser jesuita es "luchar", no solo trabajar. "Luchar por la fe" y, más sorprendente aún, "luchar por la justicia". Así lo exigía la realidad y así lo dijo la Congregación General XXXII (D 2. 2). Su muerte confirmó lo que la misma congregación había previsto lúcidamente: "No trabajaremos en la promoción de la justicia sin que paguemos un precio" (D 4. 46).

Los mártires de la UCA lo hicieron cada uno según sus talentos, y es bueno recordarlo para que todos nos podamos sentir cuestionados y animados. Permítanme detallarlo mínimamente. Ellacuría: 59 años, filósofo y teólogo, rector; repensó la universidad desde y para los pueblos crucificados; puso todo su peso para combatir la opresión y represión, y para conseguir una paz negociada. Segundo Montes: 56 años, sociólogo, fundador del Instituto de Derechos Humanos de la UCA; se concentró en el drama de los refugiados dentro del país y, sobre 
todo, de los que tenían que abandonarlo, los emigrantes, que entonces huían de la represión violenta y ahora del hambre y la falta de trabajo; visitaba los campos de refugiados en Honduras. Ignacio Martín-Baró: 47 años, psicólogo social, pionero de la psicología de la liberación, fundador del Instituto de Opinión Pública de la UCA para facilitar que se conociese la verdad y dificultar que ésta quedara oprimida por la injusticia; cada fin de semana visitaba comunidades suburbanas y campesinas con las que celebraba la eucaristía. Juan Ramón Moreno: 56 años, profesor de teología, maestro de novicios y maestro del espíritu, acompañante de comunidades religiosas; en Nicaragua participó en la campaña de alfabetización. Amando López: 53 años, profesor de teología, antiguo rector del seminario de San Salvador y de la UCA de Managua; en ambos países defendió a perseguidos por regímenes criminales, a veces escondiéndolos en su propia habitación. Por último, Joaquín López y López: 71 años, el único salvadoreño de nacimiento, hombre sencillo y de talante popular; trabajó en el colegio "Externado de San José", fue el primer secretario general de la UCA en 1965 y después fundó Fe y Alegría, institución de escuelas populares para los más pobres.

Fueron muy distintos, pero todos ellos fueron seguidores de Jesús y jesuitas. Es lo que nos dejan. En ellos podemos mirarnos para saber lo que debemos ser y hacer. Digamos una palabra sobre lo que fue más suyo.

Seguidores de Jesús. Reprodujeron en forma real, no intencional o devocionalmente, la vida de Jesús. Su mirada se dirigió a los pobres reales, aquellos que viven y mueren sometidos a la opresión del hambre, la injusticia, el desprecio, y a la represión de torturas, desaparecimientos, asesinatos, muchas veces con gran crueldad. Y se movieron a compasión. "Hicieron milagros", poniendo ciencia, talentos, tiempo y descanso al servicio de la verdad y de la justicia. Y "expulsaron demonios". Ciertamente, lucharon contra los demonios de fuera, los opresores, oligarcas, Gobiernos, Fuerza Armada, y de ellos defendieron a los pobres. No les faltaron modelos: Rutilio Grande y monseñor Romero. Y fueron fieles hasta el final, en medio de bombas y amenazas, con misericordia consecuente. Murieron como Jesús, y han engrosado una nube de testigos, cristianos, religiosos, también agnósticos, que han dado su vida por la justicia. Estos son los "mártires jesuánicos", referente esencial para los cristianos y para cualquiera que quiera vivir humana y decentemente en nuestro mundo. Su bautismo fue de Espíritu y de sangre. Y siguieron a Jesús.

Con el espíritu de san Ignacio. En este punto me voy a detener un poco más, pues hoy se habla mucho de espiritualidad ignaciana; creo que nos pueden ayudar a historizar a san Ignacio ciertamente en el Tercer Mundo y a hacerlo útil para comprender mejor a Jesús.

El otro Ignacio, Ellacuría, hizo una relectura de los Ejercicios desde la realidad del Tercer Mundo. Tres puntos me parecen fundamentales, y pueden fungir como presupuestos ignacianos de la opción por los pobres y la lucha por la jus- 
ticia. (1) Mirar la realidad de nuestro mundo y captarla como "pueblos que están crucificados". Ante ellos, la reacción fundamental - sin necesidad de discernimiento- es "hacer redención". (2) Ser honrados con nosotros mismos, jesuitas, y preguntarnos "¿qué hemos hecho para que esos pueblos estén crucificados y qué vamos a hacer para bajarlos de la cruz?". Y (3) tomar en serio - quizás lo más difícil y menos frecuente- que hay dos modos de caminar en la vida, de ser jesuitas y de construir la sociedad y la universidad. Son caminos opuestos y están en pugna. Uno es el camino de la pobreza, que lleva a oprobios y menosprecios - hoy diríamos humillaciones, difamaciones, amenazas - , y de ahí a la humildad, a la hondura de lo humano, a la verdadera vida. El otro es el camino de la riqueza, que lleva a los honores mundanos y vanos - hoy diríamos al prestigio entre los grandes de este mundo-, y de ahí a la arrogancia, a una vida falseada, personal e institucional. En resumen, uno conduce a la salvación - humanización- y el otro a la perdición - deshumanización-. Se trata de ganar o perder la vida, como dice Jesús, y de estar dispuestos a pagar el precio.

En términos de estructuras, Ellacuría insistía en que hay que elegir entre una civilización de la pobreza - afín a una civilización del trabajo- y una civilización de la riqueza - afín a una civilización del capital-. Ésta, que predomina en el mundo, ha generado una civilización gravemente enferma. Aquélla, la que hay que construir, puede revertir la historia y sanar la civilización.

Estos tres puntos, pueblo crucificado, necesidad de liberación y camino de la pobreza - más la honradez con nosotros mismos-, son, en mi opinión, lo que más resplandece en la ignacianidad de los mártires de la UCA y lo que mejor explica por qué acabaron como acabaron. En la tradición de san Ignacio, ciertamente hay otras muchas cosas importantes a tener en cuenta: el "magis", "a mayor gloria de Dios", "en todo amar y servir", "el bien cuanto más universal más divino" - todo lo que se menciona con frecuencia en la explosión ambiental de ignacianidad que hoy existe-. Los tres puntos que hemos mencionado, en mi opinión, son más fácilmente comprensibles, también, para los no iniciados en la ignacianidad, y ciertamente para los pobres. Y, en mi opinión, tienen menos peligro de perderse en el ámbito de lo conceptual e intencional; expresan realidades claramente históricas y verificables.

En este contexto, me parece oportuno recordar un hecho singular: los mártires de la UCA nunca discernieron si era voluntad de Dios permanecer en el país, con riesgos, amenazas y persecuciones, o salir. Ni se les ocurrió. Para ver cuánto de explícitamente ignaciano había en la realidad de ese proceder, pienso que hay que ir al primer tiempo de hacer elección: "sin dubitar ni poder dubitar" (Ejercicios, n. ${ }^{\circ}$ 175). Hay que preguntarse "qué movía y atraía la voluntad": si era "Dios, nuestro Señor" comunicándose al alma, como en la formulación de san Ignacio, o si eran realidades históricas: "el sufrimiento del pueblo" que no dejaba vivir en paz; "la vergüenza que daba abandonar al pueblo"; "la fuerza 
cohesionante de la comunidad"; "el recuerdo enriquecedor de monseñor Romero, de nueve sacerdotes y cuatro religiosas asesinadas"; o incluso el "haberse acostumbrado a la persecución". Pienso que todo ello movía la voluntad e iluminaba las decisiones y el camino a seguir. En el lenguaje de los Ejercicios, quizás podamos decir que en ello, y a través de ello, Dios estaba realmente causando el sin dubitar ni poder dubitar. Pero Dios no actuaba a través de cualquier cosa, sino de las que hemos mencionado.

El Espíritu de Dios mueve a caminar, pero su fuerza impulsante pasaba a través del pueblo sufriente. Así ha parafraseado Pedro Casaldáliga el conocido poema de Antonio Machado sobre el propio caminar:

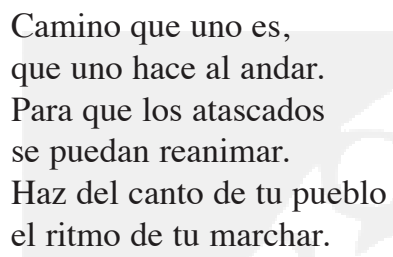

Así, pienso yo, discernieron los jesuitas de la UCA. Se dejaron atraer y llevar por la realidad. Es la sinergia de Dios y del pueblo sufriente. Y no se me ocurre otra manera de formular, quizás de explicar, por qué se quedaron.

Quisiera terminar esta reflexión sobre su ser jesuitas recordando que "murieron en comunidad". Pudo no haber sido así; pudiera haber sido asesinado sólo Ellacuría, el "enemigo" principal. Pero hay una verdad importante - providencial si se quiere - en que su muerte fuese "en comunidad". Así había sido su vida y trabajo, con alegrías y tensiones, con virtudes y pecados, pero siguiendo una sola línea bien trazada. Y así expresaron que la Compañía está hecha de "todos". Es "cuerpo", no suma de individuos, algunos de ellos geniales, otros normales.

Esta comunidad de "seis jesuitas" se integró en una comunidad mayor, el cuerpo de la Compañía universal, lo que es bueno tener siempre en cuenta. Cuarenta y nueve son los jesuitas que han muerto en el Tercer Mundo, asesinados de una u otra forma, después de la Congregación General XXXII. Entre ellos se cuentan tres estadounidenses. Francis Louis Martiseck: 66 años, nacido en Export, Pennsylvania, y muerto por arma de fuego en Mokame, India (1979); Raymond Adams: 54 años, nacido en Nueva York y muerto por arma de fuego en Cape Coast, Ghana (1989); y Thomas Gafney: 65 años, nacido en Cleveland, Ohio, y asesinado en Katmandú, Nepal (1997).

No es infrecuente recordar "las glorias de la Compañía", las reducciones del Paraguay, Mateo Ricci en China... Hoy, estos mártires, unos más famosos, otros menos, son la gloria de la Compañía. Y sobre todo son ellos los que mantienen a la Compañía con vida. El 19 de marzo de 1977, una semana después del asesinato del padre Rutilio Grande, el padre Arrupe escribió: 
Éstos son los jesuitas que necesitan hoy el mundo y la Iglesia. Hombres impulsados por el amor de Cristo, que sirvan a sus hermanos sin distinción de raza o de clase. Hombres que sepan identificarse con los que sufren, vivir con ellos hasta dar la vida en su ayuda. Hombres valientes que sepan defender los derechos humanos, hasta el sacrificio de la vida, si fuera necesario.

\section{Julia Elba y Celina: el pueblo crucificado}

Con los jesuitas murieron asesinadas dos mujeres: Julia Elba Ramos, de 42 años, cocinera de una comunidad de jóvenes jesuitas, pobre, alegre e intuitiva, y trabajadora toda su vida. Y su hija Celina, de 15 años, activa, estudiante y catequista; con su novio habían pensado comprometerse en diciembre de 1989. Se quedaron a dormir en la residencia de los jesuitas, pues allí se sentían más seguras. Pero la orden fue "no dejar testigos". En las fotos se nota el intento de Julia Elba de proteger a su hija con su propio cuerpo. Sobre Julia Elba, hace unos días escuché este testimonio de una mujer que la conoció bien:

Le digo que era muy humana porque sentía el dolor de los demás. Yo viví un tiempo en la casa de ella. Era una persona bien amistosa, sabía llevarse con los demás. Ella tenía 33 años y yo 19. Ella y yo teníamos muchas cosas en común; comenzamos a trabajar desde muy chiquitas. Ella había trabajado desde los 10 años en los cafetales [...] Era una mujer muy fuerte. Siempre me enseñó a que no me dejara, que no me acobardara ante los problemas. Fue una mujer sufrida, pero fuerte. Me enseñó a ser una mujer de valía, que no dependiera de los otros, sino de mí misma.

Como Julia Elba hay centenares de millones de hombres y mujeres en nuestro mundo. Son inmensas mayorías que perpetúan una historia de siglos: en la América conquistada y depredada por los españoles en el siglo XVI; en el África esclavizada ya en el siglo XVI y expoliada sistemáticamente por los europeos en el siglo XIX; en el planeta que sufre hoy la globalización opresora bajo la égida de Estados Unidos. Sufren la muerte rápida de la violencia y de la represión, y sobre todo la muerte lenta de la pobreza y de la opresión. Sin comparación posible, sufren más que nadie las consecuencias de nuestros desmanes. En guerras e invasiones: Afganistán, Irak, Palestina; en el manejo de la medicina y farmacia: malaria, sida; en pésima ecología: inundaciones, desertificación, pérdidas en la agricultura; en las catástrofes naturales: la inmensa mayoría de quienes mueren en los terremotos no pueden construir casas con acero suficiente, viven en la laderas de los montes y en las riberas de los ríos, o junto a las vías del tren...

Hay más riqueza en la Tierra, pero hay más injusticia. África ha sido llamada "el calabozo del mundo", una "Shoá" continental. 2,500 millones de personas sobreviven en la Tierra con menos de 2 euros al día y 25,000 personas mueren diariamente de hambre, según la FAO. La desertificación amenaza la 
vida de 1,200 millones de personas en un centenar de países. A los emigrantes les es negada la fraternidad, el suelo bajo los pies.

Estas palabras de Pedro Casaldáliga son del año 2006. Ni el G-7, ni el G-8, ni ahora el G-20 han hecho nada significativo para revertir esta historia. Recordar hoy los ideales del milenio es burla y ofensa a los pobres. En un año, el número de hambrientos ha aumentado en cien millones, y cada cinco segundos un niño muere de hambre; asesinado, puntualiza Jean Ziegler, pues es muy posible eliminar el hambre.

Son "el siervo doliente de Yahvé" en nuestros días; "el pueblo crucificado", lenguaje que no es usado y que políticamente sería "totalmente incorrecto". Sus hombres y mujeres mueren inocentemente, pues no han cometido el "pecado" de monseñor Romero o Ignacio Ellacuría, simplemente están allí. Mueren cruelmente, con gran frecuencia después de una vida de grandes sufrimientos. Viven y mueren anónimamente. Son desconocidos los cinco millones de hombres y mujeres que han muerto en el Congo, en una guerra fabricada para que el coltán termine en las megaempresas de misiles, telefonía y computación del mundo de abundancia. Y mueren indefensamente. En serio, ¿quién defiende a esos pueblos? ¿Quién arriesga algo importante para bajarlos de la cruz?

Los mártires jesuánicos - algunos - son conocidos y venerados, pero no el pueblo crucificado. Peor todavía si, aun sin pretenderlo, aquéllos ocultan a éste. Ellacuría no vivió ni murió para que el brillo de su figura opaque el rostro de Julia Elba.

Puede parecer absurdo, pero me he preguntado quién es más mártir, Ellacuría o Julia Elba, quién reproduce más la cruz de Jesús. Los mártires jesuánicos expresan mejor la decisión y la libertad para arriesgar la vida, pero expresan menos la negrura de la injusticia cotidiana, la dificultad de simplemente vivir. La muerte de las mayorías asesinadas, por su parte, expresa menos el carácter activo de lucha, pero expresa más la inocencia histórica — pues nada han hecho para merecer la muerte - y la indefensión — pues ni posibilidad física han tenido de evitarla - . Esas mayorías son las que más cargan con un pecado que las ha ido aniquilando poco a poco en vida y definidamente en muerte. Son las que mejor expresan el ingente sufrimiento del mundo. Sin pretenderlo y sin saberlo, "completan en su carne lo que falta a la pasión de Cristo". No "añaden", como puntualizan los exegetas, pero sí "reproducen".

Los jesuitas de la UCA no fueron asesinados por fidelidad kantiana a ideales universales de verdad y justicia, sino por defender a estos pueblos crucificados. Sin recordar a los millones de crucificados, no se les entiende. Sería como pretender entender la cruz de Jesús sin recordar a los pobres desgraciados a los que ayudó Jesús en su postración y a quienes defendió de fariseos, escribas, herodianos y sumos sacerdotes. 
Una última reflexión creyente: de los mártires de la UCA, unos fueron más parecidos a monseñor Romero: los jesuitas; otros fueron más parecidos al pueblo crucificado: las dos mujeres. Mirándolos a ellos y ellas en su conjunto, podemos decir que con ellos y ellas Jesús y su Dios pasaron por este mundo cargando con la cruz. Pero también hay que decir que, contra toda apariencia, en ellos y ellas pasó el Dios de la salvación. Así lo escribió el P. Ellacuría con rigor científico. Por mi parte he escrito que "fuera de los pobres - y de las víctimasno hay salvación".

Para terminar este punto, permítanme dos breves reflexiones. La primera es que entre los victimarios, asesinos directos o constructores y gestores de estructuras opresoras, hay cristianos bautizados, a veces educados por instituciones cristianas. La segunda es que, al parecer, en los procesos de canonización no saben qué hacer con los mártires jesuánicos, los mártires por la justicia. Y, ciertamente, en esos procesos no hay lugar para las mayorías de hombres y mujeres de los pueblos crucificados. Ojalá se repiensen estos procesos. Y, canonizados o no, ojalá la Iglesia se desviva por dar dignidad a las mayorías que han cargado con la cruz en vida y en muerte. Son los preferidos de Dios.

\section{Qué piden y qué dan los mártires de la UCA}

Para ellos no piden nada. Nuestra conciencia es la que nos apremia: "algo hay que hacer". Es importante no olvidarnos de ellos; guardarles cariño y agradecimiento. También es importante trabajar por y exigir que se esclarezca la verdad de los asesinatos y se juzgue a sus responsables, pues no hay modo de arreglar este mundo si la mentira, el encubrimiento y la impunidad siguen intactos. Pero no basta. Debemos dejarnos interpelar y preguntarnos qué nos piden los mártires.

En mi opinión, nos piden, en virtud de ser lo que han sido, "proseguir su ser y hacer". Y comenzar como ellos, sin temor a plantear la vida, la vocación y el trabajo en términos de con-versión, correlativa a la tarea de re-vertir la historia. Ejemplo insigne de "conversión", de "vuelco" en el modo de ser y hacer - aunque no le gustaba que se hablara de él en términos de conversión- fue monseñor Romero. De la conversión de los mártires de la UCA - que comenzó a irrumpir en unos lejanos ejercicios de 1969-, surgieron modos fundamentales de ser y de actuar: la honradez con lo real, la misericordia consecuente sin medir costos, el trabajo por una civilización de la pobreza. Y, sorprendentemente, también dejarnos salvar por los pobres.

Vamos a ejemplificarlo concentrándonos en lo que para ellos fue y exigió la universidad, aunque análogamente creo que pudiera decirse del trabajo pastoral, asistencial, de derechos humanos... Y fue una exigencia seria, pues no suele ocurrir que, ni siquiera tras una conversión, se asesine a jesuitas que trabajan en una universidad. 
El 12 de junio de 1982, la Universidad de Santa Clara otorgó al P. Ignacio Ellacuría un doctorado honoris causa, quien al recibirlo pronunció un importante discurso. Releído hoy, aun teniendo en cuenta las diferencias de tiempo y lugar, sigue ofreciendo luz, dirección e impulso para construir una universidad jesuita de inspiración cristiana. Habrá que adaptar sus palabras creativamente, pero sería temeridad ignorarlas. Veamos brevemente algunos de sus elementos más novedosos, cuestionantes y fructíferos, citando algunas de sus palabras.

A quién se debe la universidad. Toda universidad tiene que ver "con el saber y con un determinado ejercicio de la realidad intelectual", y en ello las universidades jesuitas no se distinguen de otras. También lo pensaba Ellacuría, y exigía que el saber fuese lo más riguroso posible y que la investigación y la docencia fuesen de calidad. Esta exigencia la damos por sentada y no vamos a insistir en ello. Pero insistía también en algo que no es tan evidente ni comúnmente aceptado: "La universidad es una realidad social y una fuerza social, marcada históricamente por lo que es la sociedad en la que vive y destinada a iluminar y transformar, como fuerza social que es, esa realidad en la que vive, de la que vive y para la que debe vivir".

Esto lleva, entre otras, a una pregunta crucial: ¿a quién se debe y ante quién es responsable la universidad? Condición de su existencia es una variedad de realidades y agentes sociales: los jesuitas y su tradición universitaria; la institución eclesial que, según los casos, dará su aprobación; la comunidad académica e intelectual en el pasado y en el presente; los que la hacen factible económica y financieramente - a veces, políticamente - ; el estudiantado... A todo esto hay que atender, pero la universidad no se debe últimamente a nada de ello. Y para responder no bastan respuestas universales o que se piensa son conocidas de antemano.

En el caso de todo el Tercer Mundo, mayoría en la humanidad, distinto y antagónico a las minorías del planeta, a pesar del ideal de equidistancia que sugiere el término "globalización", la realidad a la que se debe la universidad y a la que tiene que servir es un mundo de pobreza e ignominia, en muy buena parte un mundo de opresión y represión - y a esa conclusión se llega sin dubitar ni poder dubitar - . Los medios e instrumentos de servir deben ser estrictamente universitarios, pero lo central del servicio se descubre fuera de la universidad: liberar de todo tipo de opresión. En definitiva, "bajar de la cruz a esos pueblos crucificados". Sin dar prioridad a ese servicio, una universidad puede ser un centro de saber, junto a otros, más o menos competente y competitivo, pero no es una universidad de inspiración cristiana. Y no hay que darlo por supuesto, pues la tentación de lo contrario siempre está al acecho.

En términos cristianos, es la opción de la universidad por los pobres y las víctimas. La tarea de la universidad es lograr que "los pobres", los que no dan la vida por supuesto, tengan vida; y que "las víctimas", los que tienen a los po- 
deres de este mundo en contra, estén defendidos de cualquier poder opresor. Eso lo debe hacer la universidad como un todo, haciendo el mejor uso de la razón en su docencia, investigación, proyección y comportamiento social $-\mathrm{y}$ sin confundirlo con la asistencia a estudiantes desfavorecidos, por benemérito que esto sea, por otros capítulos-.

"Ciencia de los que no tienen voz". Decía Ellacuría: "La universidad debe encarnarse entre los pobres intelectualmente", lo cual en la realidad, e incluso en el concepto, es de difícil comprensión. Pero se hace más comprensible al mencionar la finalidad de tal encarnación: "Ser ciencia de los que no tienen voz, el respaldo intelectual de los que en su realidad misma tienen la verdad y la razón, aunque sea a veces a modo de despojo, pero que no cuentan con las razones académicas que justifiquen y legitimen su verdad y su razón".

Entre nosotros, en El Salvador, esas palabras recuerdan a las de monseñor Romero: "Estas homilías quieren ser la voz de los sin voz" (homilía del 29 de julio de 1979). Y la razón era para defenderlos de los que tienen demasiada voz. Es notable que al buscar un punto de contacto entre razón universitaria y palabra eclesial, Ellacuría no incursionase por ejemplo en la temática de teoría y praxis, de falibilidad o infalibilidad, duda o certeza, sino en el ámbito de la defensa de oprimidos y víctimas. Aquí la analogía entre palabra pastoral y palabra universitaria se convierte en univocidad.

Monseñor Romero prosiguió: "Por eso, sin duda, [estas palabras] caen mal a aquéllos que tienen demasiada voz", y la Iglesia de monseñor Romero fue duramente perseguida. Lo mismo ocurre con la razón universitaria propuesta por Ellacuría. En su discurso recordó las amenazas, ataques y persecución a la UCA en aquellos años. Lo importante, sin embargo, es su reflexión programática, válida hasta el día de hoy: "En un mundo donde reina la falsedad, la injusticia, la represión, una universidad que luche por la verdad, por la justicia y por la libertad no puede menos que verse perseguida". Por esa razón es importante preguntarse cuánto de persecución sufre o no sufre una universidad cristiana; de parte de quién la sufre y de parte de quién recibe halagos; y cómo se comporta ante una cosa u otra.

Cuando la razón y la palabra, universitaria o pastoral, no es light y amorfa, sino que tiene peso y aristas, es más cortante que espada de dos filos. Y entonces el mundo que se presenta como tolerante, defensor de la libertad de pensamiento y de expresión, busca defenderse de una razón compasiva y de la palabra de un Dios de los pobres. Hace cuarenta años, hasta la CIA buscó defenderse de Medellín y de la teología de la liberación, pues les daba miedo - "ponen en peligro nuestros intereses", se decía en el Informe Rockefeller-. En América Latina, Gobiernos y Fuerzas Armadas asesinaron a docenas de sacerdotes, entre ellos cuatro obispos. Ese mismo miedo pueden generar las universidades a los poderosos. 
Universidad "en pobreza" y "sin poder". Es lo que Jesús pide a los discípulos cuando los envía a realizar la misión, es decir, a realizar una tarea. "No tomen nada para el camino". "No sean como los señores de este mundo que oprimen con su poder". Esto hay que historizarlo adecuada y realistamente, pero no se debe ignorar eficazmente como si no tocase en nada la labor de una universidad.

En la meditación de las Dos Banderas, san Ignacio es muy claro en que pobreza y sin poder son caminos de perfección, pero son también caminos de vida, humanización. E insiste en que ambas cosas están en oposición dialéctica a la riqueza y el poder. Éste es el san Ignacio de Manresa. Después, como general de la Compañía, tuvo que historizarlo - y no fue fácil-. El apostolado exigía recursos y los jesuitas entraron, como por necesidad, en relación con bienhechores. Esto les acercó al mundo de la riqueza, de los honores y del poder: reyes, damas de la nobleza, cardenales... A san Ignacio le ocupó seriamente el problema, y buscó soluciones. Un ejemplo emblemático conocido es la recomendación a Laínez y Salmerón cuando fueron como teólogos al Concilio de Trento, mundo de poder, ciertamente eclesiástico e indirectamente también civil. Y les ordenó vivir y pasar las noches en hospitales de pobres. Era una forma de vivir las Dos Banderas en una situación objetiva de riqueza y de poder.

Hoy, por lo que toca a servir en pobreza, se debiera alcanzar el nivel de austeridad, rechazar lujos en edificios y templos, y huir de solemnidades mundanas $\mathrm{y}$ vanas, aunque eso sea aceptado e incluso esperado socialmente. Y, ciertamente, evitar - en comparación con pobres y clases medias bajas- desigualdades lacerantes en el modo de comportarse.

Por lo que toca al sin poder, no se debe ceder el poder que proviene del "saber", pues de esa forma el saber queda en manos de quienes normalmente lo usan para ocultar la verdad y oprimir a los pobres. Pero hay que evitar la arrogancia y el sometimiento de otros que genera el poder. Y el gusto que, más o menos conscientemente, produce estar cerca de los poderes reales, civiles o eclesiásticos.

Por lo que toca a la arrogancia, no hay mejor remedio que dejar que los pobres sean nuestra buena noticia, sobre todo cuando, sin decirlo, nos perdonan. $Y$ asumido con humildad, mucho ayuda la persecución y el martirio.

Y una última reflexión, en forma de aclaración, sobre la "excelencia académica". Esta forma parte de la tradición de la educación de la Compañía, pero cualquier maestro de la sospecha se preguntará si hoy no se está encubriendo algo al insistir en ella, y en qué consiste. Para mí el problema está en adecuar, sin discusión, excelencia académica y excelencia universitaria $-\mathrm{y}$ en querer acercarse a otras afamadas instituciones universitarias-. Aquélla es necesaria para que exista ésta, pero no es lo mismo. Y peor aún si la insistencia en la excelencia académica llevara a que disminuya o se tergiverse la excelencia uni- 
versitaria. Ya hemos dado nuestra opinión sobre cómo se mide la excelencia de una universidad: desde la compasión que configura una sociedad en la línea de la verdad, la justicia, la liberación y la humanización. Para ello, la academia es necesaria y sumamente importante, pero no es la finalidad última. En una universidad es instrumento esencial, pero no el fin esencial.

De hecho, así ha sido en las universidades de los jesuitas. Según épocas, los saberes han sido instrumentos importantes para defender la fe, para que la Iglesia adquiera reconocimiento y prestigio, para elevar el nivel de conocimiento de determinados grupos sociales... Y para ello se ha necesitado excelencia académica. Pero lo que hemos propuesto va más allá. Bajar de la cruz al pueblo crucificado significa que sea posible la vida, la dignidad, la fraternidad en el mundo de pobres y oprimidos. Y, además, desde esta perspectiva, se puede retomar la excelencia académica en sentido más humanizante, ahora como un elemento de la excelencia universitaria y sin los peligros mencionados, de manera que se transforme en excelencia académica "integral".

La razón está en que en nuestro mundo reina la falsedad, no solo la ignorancia. Buscar la verdad - con excelencia - no es entonces sólo hacer avanzar el saber, sino desenmascarar la mentira establecida. Predomina además la ideología, que tiene una dimensión estructural-institucional y que quiere defender con el saber intereses muy frecuentemente injustos. La excelencia del conocimiento, en cuanto conocimiento, exige entonces conversión de la inteligencia para superar falsedad e ideología. Y eso se logra, pienso yo, cuando nos dejamos afectar, también intelectualmente, por la realidad crucificada. Y no solo para sanar la realidad, sino para sanar nuestro conocimiento y expandir sus horizontes. Esto cuestiona la manera ordinaria - ingenua, en el mejor de los casos - de entender la excelencia académica y le ofrece una nueva dirección. El servicio universitario a la liberación de un mundo oprimido, lejos de minarla, la robustece.

Y no hay que olvidar que la excelencia académica convencional necesita ayudas urgentes, pues la empuja el establishment, que busca generar ideologías a su favor y graduados altamente competentes para mantener el statu quo. Mucho más difícil es encontrar fuerzas y dinamismos sociales que muevan a transformar la realidad y sean asumidos por una universidad. Estos dinamismos vienen de los pobres, las víctimas, los mártires.

\section{La gracia de los mártires}

Hemos recordado a mártires. Su vida y su muerte son de gran dureza, y por eso mis palabras pueden sonar fuertes. Pero también es verdad que a ellos se dirigen las bienaventuranzas de Jesús. Y que para nosotros son - pueden seruna bendición: nos animan a entregarnos a los demás y a tener esperanza; ánimo que no se encuentra, con esa fuerza, en ninguna otra parte, ni en la liturgia del templo ni en la actividad de la academia. 
En Navidad decimos que en Jesús de Nazaret "ha aparecido la benignidad de Dios". En Semana Santa escuchamos en boca de Pilato que ese Jesús es "el hombre verdadero", "el que cargó con la realidad por amor a los pequeños". De ahí el "ecce homo". Ambas cosas, la aparición de Dios y la aparición de lo humano en un mundo en oscuridad, son una buena noticia.

Eso es lo que celebramos en este acto universitario. Los seis jesuitas de la UCA nos llevan en su fe, de la que podemos tener alguna noticia, aunque sea caminando en silencio y de puntillas. Julia Elba y Celina nos llevan en la suya, pero de manera distinta. Yo, al menos, no puedo entrar hasta el fondo en su misterio. Pero Dios sí les conoce y ellos —Dios sabe cómo - nos llevan a Dios.

Y contra toda ciencia y prudencia, los mártires generan esperanza. Miles de campesinos pobres, con familiares muertos, se juntan la víspera del 16 de noviembre en la UCA para celebrar unos con otros, rezar y cantar. Jürgen Moltmann lo ha teorizado muy bien: "No toda vida es ocasión de esperanza, pero sí lo es la vida de Jesús, quien, por amor, tomó sobre sí la cruz”.

Termino. Quiero agradecer muy sinceramente a la Universidad de Santa Clara por la oportunidad que me ha dado de dirigirles estas palabras. Me han permitido hacer presente de algún modo el sufrimiento y la esperanza de un pueblo admirable, y la memoria de mis hermanos y hermanas de la UCA. También quiero agradecerles el honor personal que me hacen. Me recuerda el cariño que me mostraron hace veinte años. Y lo interpreto como símbolo de solidaridad de esta universidad con la UCA y con todo el pueblo salvadoreño.

Mis palabras finales son las que escribí aquí hace veinte años.

Descansen en paz Ignacio Ellacuría, Segundo Montes, Ignacio Matín-Baró, Amando López, Juan Ramón Moreno, Joaquín López y López, compañeros de Jesús. Descansen en paz Julia Elba y Celina, hijas muy queridas de Dios. Que su paz nos transmita a los vivos la esperanza, y que su recuerdo no nos deje descansar en paz. 